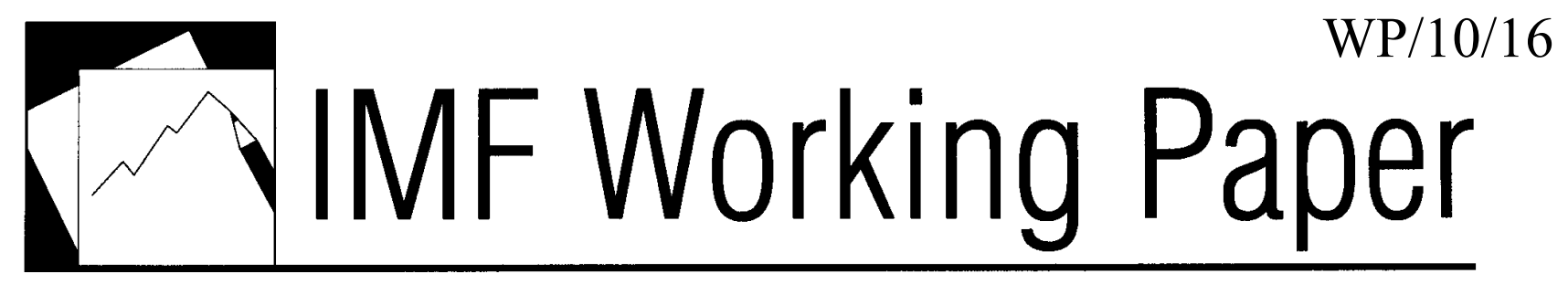

\title{
China: Does Government Health and Education Spending Boost Consumption?
}

Steven Barnett and Ray Brooks 


\title{
IMF Working Paper
}

Asia and Pacific Department

\section{China: Does Government Health and Education Spending Boost Consumption?}

\author{
Prepared by Steve Barnett and Ray Brooks ${ }^{1}$
}

Authorized for distribution by Nigel Chalk

January 2010

\begin{abstract}
This Working Paper should not be reported as representing the views of the IMF. The views expressed in this Working Paper are those of the author(s) and do not necessarily represent those of the IMF or IMF policy. Working Papers describe research in progress by the author(s) and are published to elicit comments and to further debate.

Consumption in China is unusually low and has continued to decline as a share of GDP over the past decade. A key policy question is how to reverse this trend, and rebalance growth away from reliance on exports and investment and toward consumption. This paper investigates whether the sizable increase in government social spending in recent years lowered precautionary saving and increased consumption. The main findings are that spending on health, but not education, had an impact on household behavior. The impact, moreover, is large. A one yuan increase in government health spending is associated with a two yuan increase in urban household consumption.

JEL Classification Numbers:H31, H51, H52

Keywords: China, saving, consumption, health, education

Author’s E-Mail Addresses: SBarnett@imf.org; RBrooks@imf.org

\footnotetext{
${ }^{1}$ We would like to thank Jianxiong He, Vivek Arora, Tarhan Feyzioglu, Nigel Chalk, Papa N'Diaye, Nathan Porter, Francis Vitek, and seminar participants at the People's Bank of China for helpful comments and suggestions, as well as Kessia De Leo and Imel Yu for their assistance in preparing this paper. All remaining errors are ours.
} 


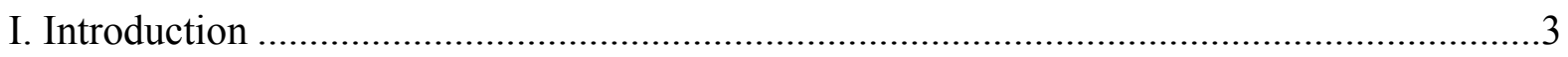

II. Consumption and Saving in China: Stylized Facts ................................................

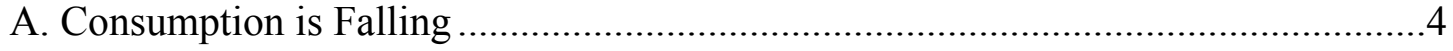

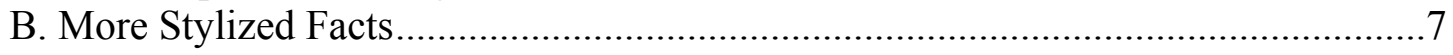

III. Reducing Precautionary Saving: A Role For Public Spending? ................................... 8

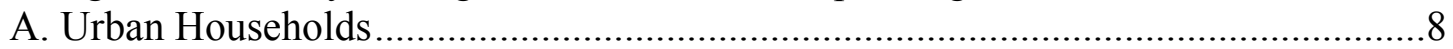

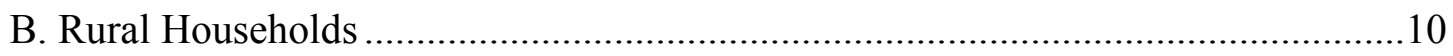

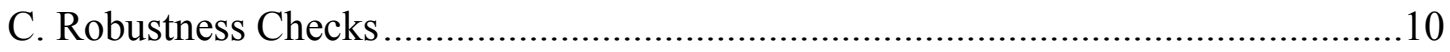

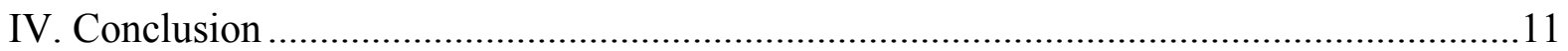

Figures

1. Consumption in China: Low and Falling ...................................................................

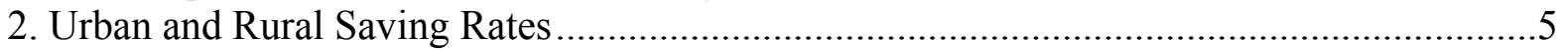

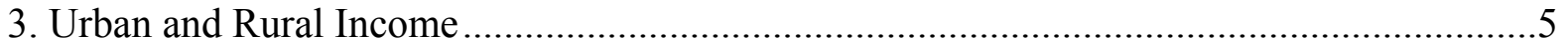

4. Indicators of Urban and Rural Consumption and Income .............................................6

5. Household Income and GDP per Capita ................................................................... 7

6. Urban Household Saving Rate by Income Group..................................................... 7

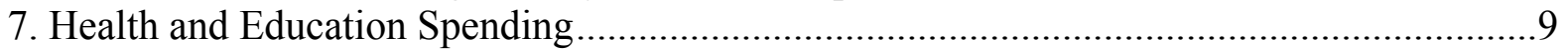

Tables

1. Urban Households: Saving and Government Spending.............................................. 12

2. Rural Households: Saving and Government Spending................................................12

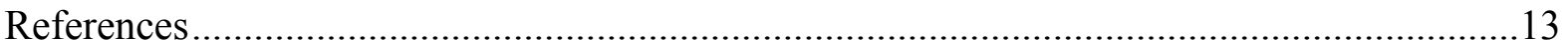




\section{INTRODUCTION}

Consumption in China is unusually low and has continued to decline as a share of GDP over the past decade. A key policy question is how to reverse this trend, and rebalance growth away from reliance on exports and investment and toward consumption. The collapse in global demand - and corresponding decline in China's export growth — is making rebalancing even more urgent.

China's low household consumption, or equivalently high saving, is often linked to precautionary motives. Government health, education, and pensions systems are underdeveloped, leaving individuals to bear a large share of the costs. As a result, households build up saving to cover these expenses, as well as to self-insure against uncertainty, especially regarding future health and pension needs. Of course, to explain both the low and declining consumption rate, precautionary motives must be large and also rising over time. Indeed, Chamon and Prasad (2008) argue this is the case, as the breaking of the "iron rice bowl" with the reforms in the 1990s - especially to state-owned enterprises-led to a breakdown of existing systems and increased household uncertainty.

An obvious channel for boosting consumption, therefore, is to reduce precautionary saving. Indeed, this has in many respects become a consistent view in the literature. To cite some examples, IMF (2007) and Blanchard and Giavazzi (2005) both emphasize reducing precautionary saving as one of the key components for rebalancing growth. The goal of this paper is to explore the empirical relationship between government health and education spending and household saving.

The main conclusion that comes out of the data is that government spending on health, but not on education, has an impact in reducing urban household saving. The impact, moreover, is large. A 1 yuan increase in government health spending was associated with a 2 yuan increase in household consumption. Total (household plus government) consumption could thus increase by as much as 3 yuan depending on the extent that government health spending takes the form of consumption instead of transfers. For rural households, on the other hand, the evidence is more mixed. Increased government health spending in rural areas appears only to have an impact on savings in the higher-income provinces.

We focus narrowly on the issue of the role of government spending, and do not attempt to answer the broader question of what is driving consumption behavior. Household income, as highlighted in Aziz and Cui (2007), is an even more important driver of consumption's falling GDP share than the saving rate. This would suggest that policies to boost household income would also bear fruit, particularly if they are combined with policies, such as improving the healthcare system, that are effective in reducing the household saving rate.

The remainder of this paper proceeds as follows. In the next section, we draw some stylized facts about consumption and saving in China. In section III, we use provincial household data 
to examine econometrically the relationship between saving and government health and education spending. The last section reviews the main findings.

\section{Consumption And SAVIng in China: Stylized Facts}

\section{A. Consumption is Falling}

Consumption as a share of GDP in China has steadily declined, and is quite low relative to other countries. This is clear in Figure 1, where the top panel shows total consumption as a share of GDP for a cross-section of countries. Since there is some substitutability between public and private consumption - government provision of free education, for example, means less need for household education spending - it is useful to look at total consumption. The second panel shows how the share of household consumption has been falling over time. Mechanically, this has been offset by rising investment and more recently by an expansion in net exports.

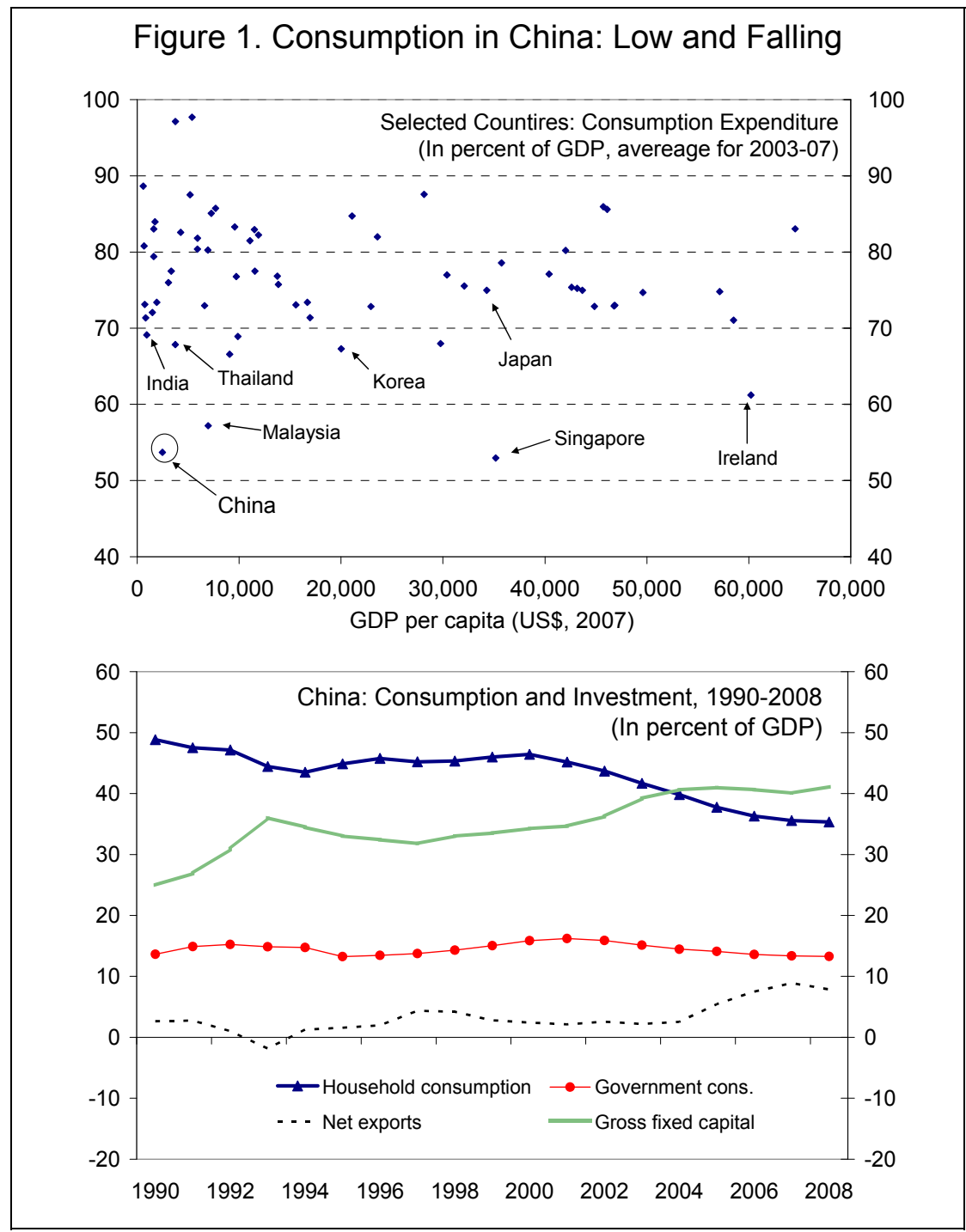


Saving rates have risen, helping explain the decline in the consumption ratio (Figure 2). From the household survey data it is clear that rural and urban households have followed quite a different path. The urban saving rate has steadily risen over time whereas rural saving has been more volatile, but has also risen. Urban households, however, account for the lion's share of economic activity and so are instrumental in the overall increase in aggregate saving (see below).

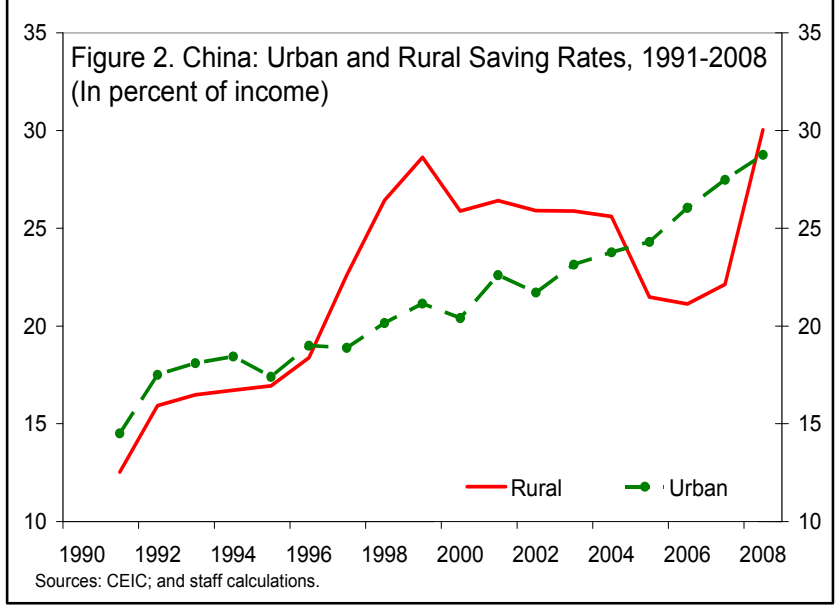

In addition to a higher saving rate, household income has also been a major factor helping to explain the decline in the consumption ratio. In per capita terms, both urban and rural household incomes have fallen steeply over time, failing to keep pace with GDP growth (Figure 3). Households are getting a declining share of the value added pie (see Aziz and Cui, 2007). From the early 1990s to 2008, urban household per capita income dropped from nearly 90 percent of GDP per capita to just under

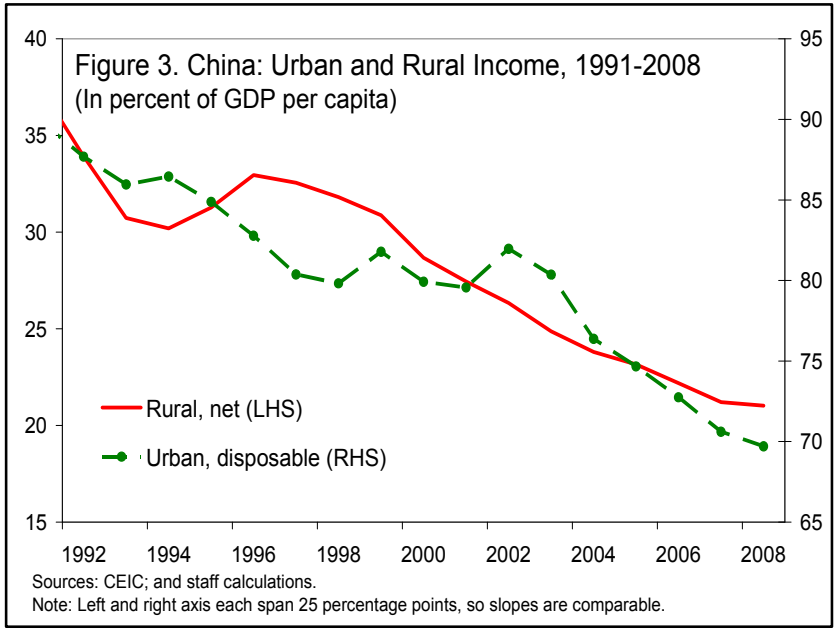
70 percent.

This decline in household's share of income has been the main culprit behind the drop in consumption (Figure 4). For urban households, roughly 60 percent of the decline in consumption since the early 1990s is attributable to a drop in disposable income as a share GDP. For rural households, falling income plays a larger role and explains around three-fourths of the decline since the early 1990s. 


\section{Figure 4. Indicators of Urban and Rural Consumption and Income}

Urban consumption as a share of income is falling whether measured by national accounts or household survey data.

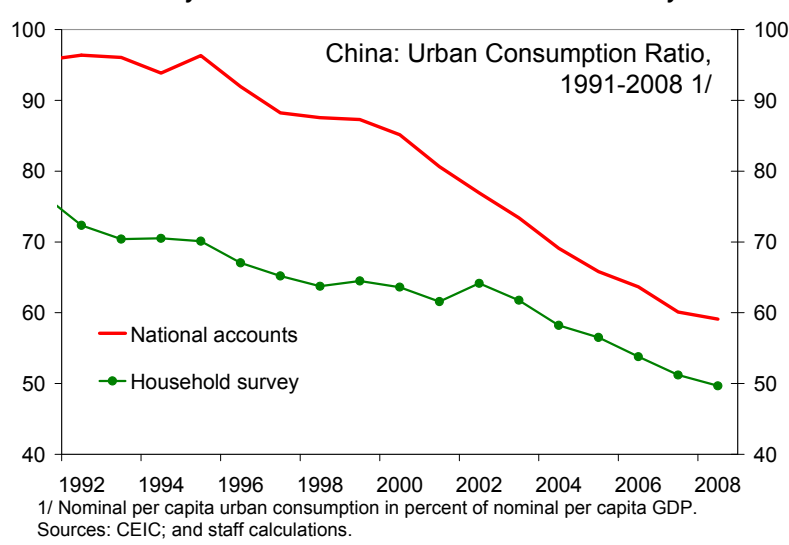

There is no clear sign of consumption smoothing in the urban household survey data...

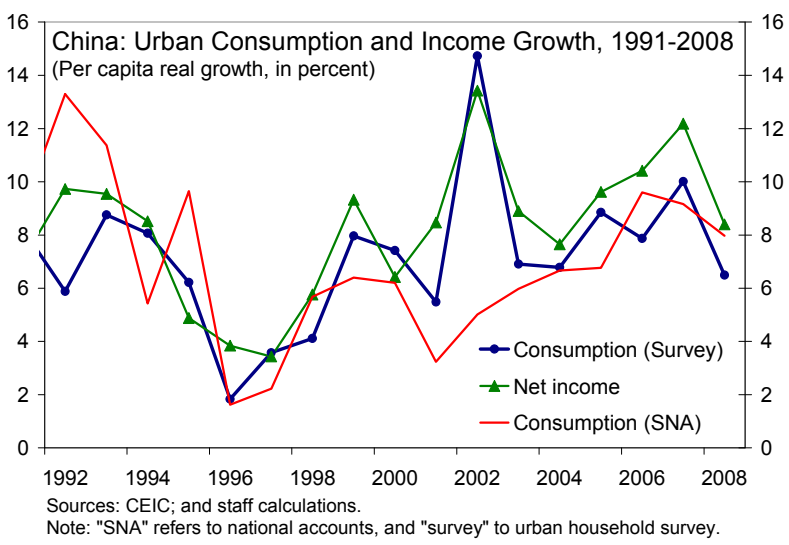

Urban income (consumption) per capita is about 3 times bigger than rural income (consumption) per capita...

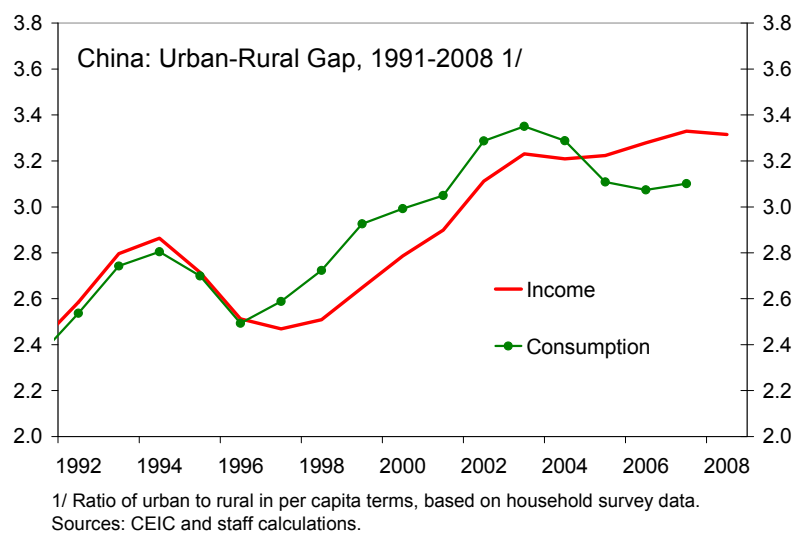

The same holds for rural consumption data, though rural consumption is a smaller share of income.

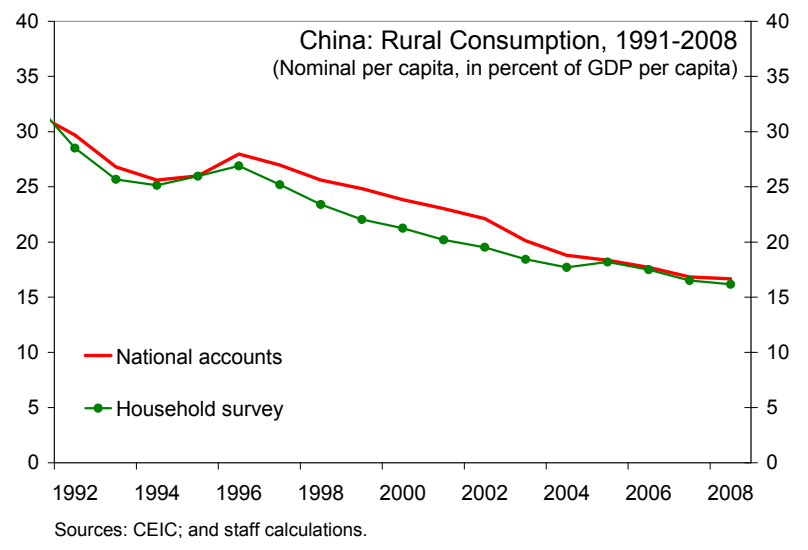

...nor for rural households.

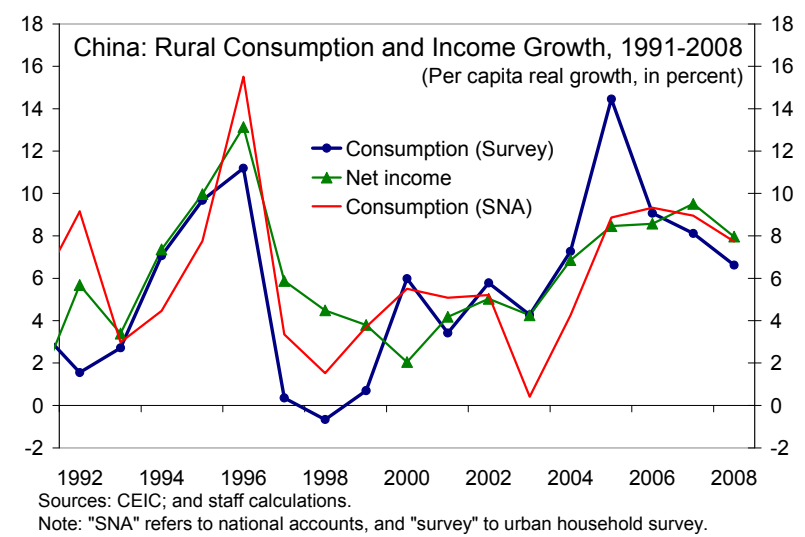

...but urbanization has dramatically increased the share of urban consumption in total consumption.

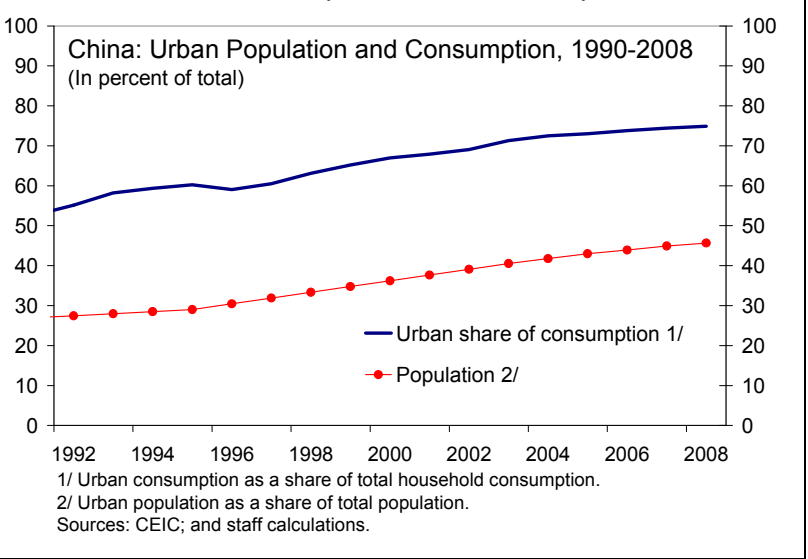




\section{B. More Stylized Facts}

Some other characteristics help put the trends in saving, consumption, and income into perspective:

First, real growth in household income and consumption has been fast (Figure 5). However, real GDP growth has been even faster. National accounts data indicate that real household consumption (CPI deflated) has grown at a remarkable $83 / 4$ percent average annual rate over the past 10 years. GDP growth, however, has been even faster at $93 / 4$ percent. Household income has also risen quickly but not as fast as the pace of GDP growth.

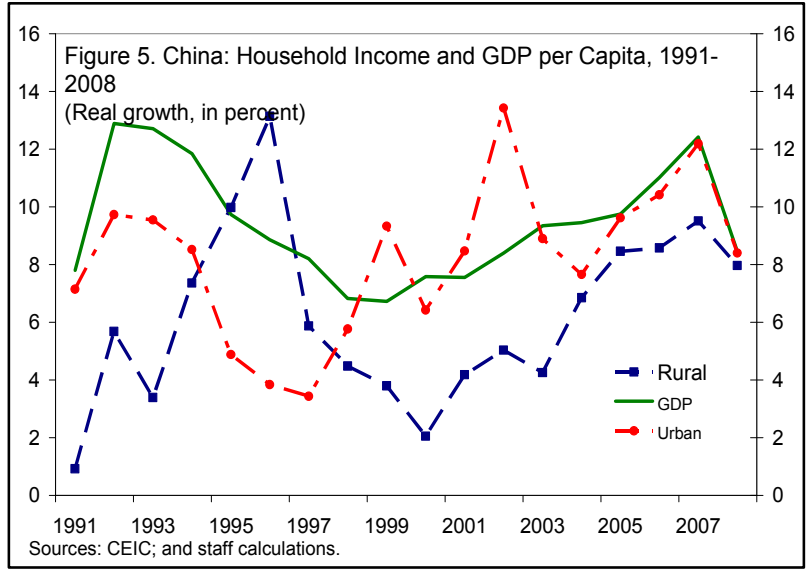

Second, the data lack any obvious signs of consumption smoothing. The volatility of consumption growth is greater than that of income growth. This is true for both urban and rural households. For the urban data, both income and consumption jump up in 2002, which Chamon and Prasad (2008) note was when improvements were made to the household survey methodology. This suggests the spike in the data that year could merely represent a break in the methodology.

Third, urban consumption accounts for three-fourths of household consumption, a share that has risen steadily in line with the pace of urbanization. Indeed, rural consumption accounts for most of the decline in the consumption to GDP ratio. Less obvious, however, is that the share of urban population has also risen significantly. Expressed in per capita terms, to control for urbanization, the urban-rural gap has widened over the sample period, but has stabilized more recently. The gap, however, remains large as urban households earn and spend roughly three times as much as rural ones. This is also relevant to the extent that saving behavior would be expected to be dependent on income levels.

Fourth, as would be expected saving is positively related to income. The trends in saving, however, also differ. Lower income groups have seen relatively little increase in saving rates and indeed saw a decline in their savings in the early 2000s (Figure 6). In contrast, higher income groups have had gradually increasing saving rates with the pace of that increase starting to accelerate around 2003.

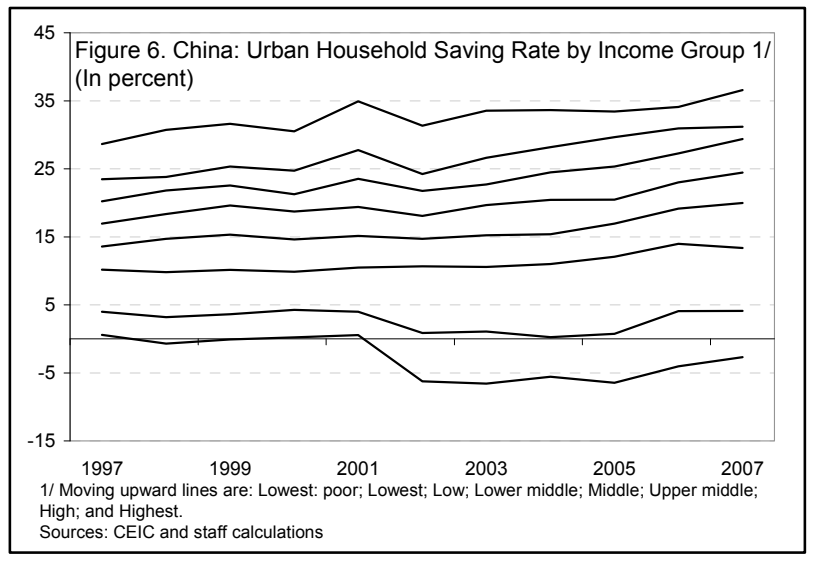




\section{Reducing Precautionary Saving: A Role For Public Spending?}

The econometric section examines whether increases in government spending on health and education have an impact on savings. Provincial data are pooled to exploit variations in provincial spending on health and education, and differences in saving rates. Data from 1994-2007 are used, but a smaller sample of 2003-07 is also employed to check robustness and control for the possibility of structural changes.

The analysis looks at urban and rural households separately. As noted above, the trends in their saving behavior differs as does their income levels, making it likely that their response to increases in government spending would not be the same. Ideally, therefore, the government spending variables used - for education and health spending-would breakdown spending into that undertaken in urban and rural areas. The provincial government spending data, however, do not distinguish between these types of spending. So the differences in results found between urban and rural behavior should be treated with some caution since it could merely reflect differences in how government spending has been allocated.

\section{A. Urban Households}

The results suggest a statistically significant relationship between health spending and urban saving (Table 1). The parameter estimate is highly statistically significant and fairly stable across the two samples and with the inclusion of education spending. The estimate is around -2 , which suggests that each 1 yuan of government health spending results in a 2 yuan decrease in saving — or, equivalently, a 2 yuan increase in consumption. This is a strong impact, as it would imply that a 1 percent of GDP increase in government health spending would boost private consumption by 2 percent of GDP and yield a total demand effect of 3 percent of GDP for every 1 percent of GDP increase in health spending.

The impact of government health spending on saving is larger than might have been expected. In this first step, government health spending simply substitutes for private health spending, which would cause the saving rate to increase. That is, for each extra yuan the government spends on health individuals could spend 1 yuan less, freeing up that 1 yuan to be allocated to additional saving and consumption — but the net impact, provided at least part of the freed up income is saved, would be an increase in the saving rate. The negative sign, therefore, indicates that government spending is not substituting for private spending and suggests that it is instead reducing the need for saving. That is, higher government health

spending seems to reduce the need for precautionary saving and frees up households ability to spend on other goods and services.

Private health care spending by urban households has fallen in recent years, suggesting that higher government spending on health care has indeed freed up resources for households for other spending or saving. Urban health care spending (from the household survey) fell by 
more than $1 / 2$ percent of urban household consumption over the past four years, as government spending on health care more than doubled to the equivalent of 3 percent of total household consumption (Figure 7). A similar picture emerges from the national accounts data, which show higher urban health care spending, but nonetheless a decline in recent years. Rural healthcare spending, however, increased over the past four to five years by $1 / 2-$ $3 / 4$ percent of rural household consumption (based on survey and national accounts data).

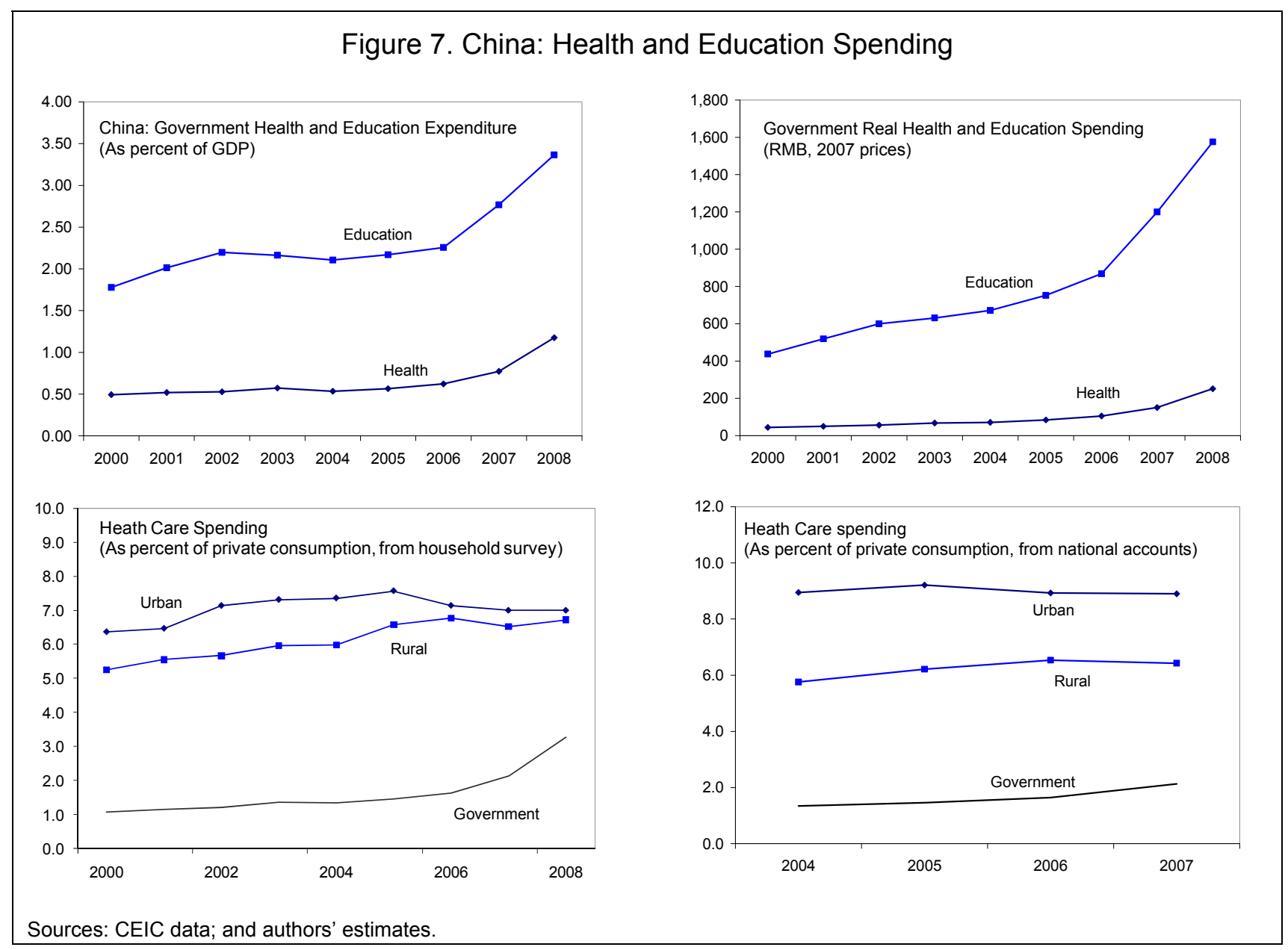

The results for education are, however, quite different. There is little evidence that higher government education spending decreases saving. The coefficient is never statistically significant, and the sign actually switches between the full sample and the latter period. The lack of a statistically significant relationship could reflect that much of the increase in government education has been toward primary and secondary education, whereas the saving is more targeted toward higher education. Moreover, the increase in government spending may not have kept pace with the rise in expected household education spending. Education spending per capita is more than five times larger than health spending and has also grown rapidly over the past four years. 


\section{B. Rural Households}

For rural households, there is little evidence that higher health spending reduces precautionary saving (Table 2). The coefficient estimate on health is never statistically significant, and for that matter is always positive, which would suggest that higher government health spending actually increases saving. This may reflect the fact that many of the rural households are subsistence consumers and would be expected to save a substantial part of the resources freed up by the government providing more health care coverage. It could also be that rural areas are receiving a smaller share of provincial health spending and so it is having much less effect than in the urban areas or the increase in public spending has been small relative to expected rural health spending needs.

Likewise, there is little evidence that an increase in education spending has an impact on saving of rural households. Again, the coefficient is always positive, and, while not statistically significant at conventional levels, is quite close to being significant in the 2003-07 sample. This would be consistent with increase government spending on education simply substituting for private spending — and the coefficient of near unity would suggest a nearly one-for-one impact.

\section{Robustness Checks}

The coastal provinces have developed faster, have higher income per capita, and tend to be more urbanized. The regressions are repeated allowing the impact to be different in the eight highest income provinces. ${ }^{2}$ This helps check the robustness of the results more generally, but also examines whether there are systematic differences in the highest income provinces.

The results for rural households suggest that government health spending in high income provinces, unlike for the whole sample, is associated with a decline in rural household savings. The magnitude, moreover, is similar to the -2 found in the urban regressions reported above. This could reflect a variety of factors, including that rural households in high income provinces are wealthier (and thus resemble urban households elsewhere) or that they are a larger beneficiary of government health spending.

The results for urban households, however, do not provide strong evidence that the impact of health spending differs in higher income provinces. The interaction term is not usually statistically significant, though it is always negative, which would suggest that the impact could be marginally stronger in higher income provinces.

Finally, the results for the impact of government health spending on urban household saving hold up to other robustness checks. Different explanatory variables are included to gauge the

\footnotetext{
${ }^{2}$ These are Beijing, Tianjin, Shangdong, Jiangsu, Fujian, Guangdong, Zhejiang, and Shanghai.
} 
impact on the statistical significance and magnitude of the parameter estimate on health spending. Variables that are added, in various combinations, include real income growth, inflation, and unemployment. The results (not reported) did not change substantially in either the whole sample or the 2003-07 sample.

\section{Conclusion}

The main finding of this paper is fairly robust. Higher government health spending reduces urban household saving and suggests that broadening coverage of public health care could have an important effect on household precautionary savings. The magnitude of the impact, moreover, is quite large and suggests that each additional yuan in government health spending boosts urban consumption by 2 yuan.

For rural households, with the exception of those in the higher income provinces, there is, however, no evidence of a relationship between government health spending and saving. There was also no evidence that higher government education spending has an impact on either urban or rural saving. This is not entirely surprising, as the precautionary saving motives are likely much higher for health than education. In both cases, an increase in government spending has competing effects on saving. First, it could increase saving by substituting public for private provision of the services, thereby freeing up household resources of which some would be saved. To reduce saving, government education or health spending would need to have an additional effect, such as reducing precautionary saving motives. Given that a large part of the savings are being generated by older generations, who are more likely to need to save for healthcare costs rather than education for their family members, it is sensible to expect that improvements in public health care are likely to have a more potent effect on household saving behavior than expanding publicly provided education.

Although past rural health care spending appears to have had little impact on consumption, the government's new health reform strategy for 2009-11 has the potential to improve health outcomes and raise rural consumption. The government has given priority to the health sector, along with other social sectors, such as education and social protection, in the $11^{\text {th }}$ five-year plan. A comprehensive study by the World Bank (2009) suggests that while progress is being made to improve China's rural health system, including by marching quickly toward universal coverage for rural areas, a number of challenges remain. Importantly, the study notes that the inequalities in China's health system reflected, at least in part, inequalities in government health spending. They note that government health expenditure disproportionately benefited the better off. This reflects the fact that over half of general government health spending supports urban insurance schemes whose members are disproportionately from higher income groups, even within urban areas. The reorientation of government spending toward the poorer rural areas and increased efficiency in the delivery of public health care will be key factors in improving health outcomes and impacting consumption behavior. 
Table 1. Urban Households: Saving and Government Spending

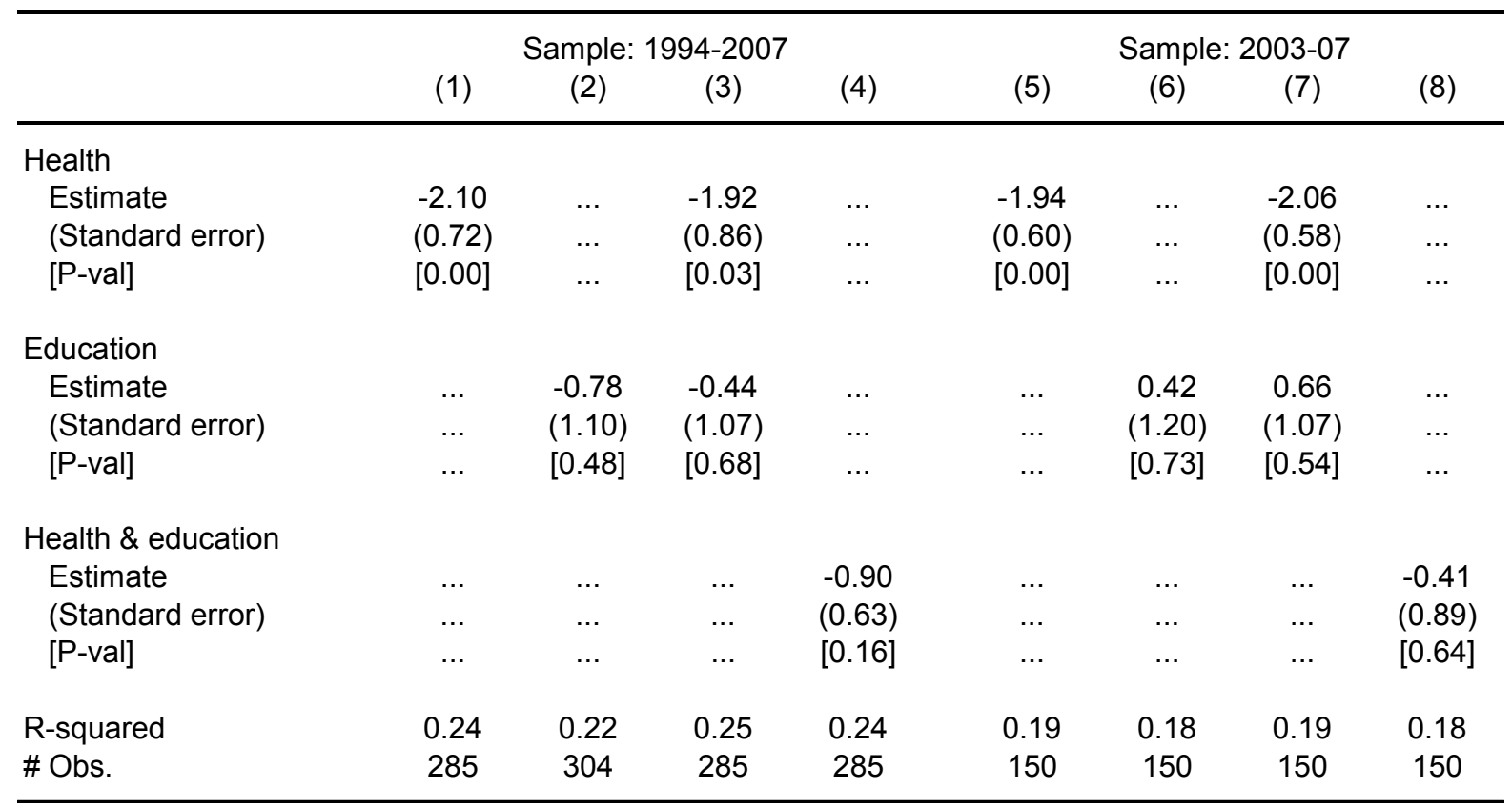

Sources: CEIC; and staff estimates.

Note: All variables are in first differences. The dependent variable is the saving rate, and government spending variables are per capita spending expressed as a share of per capita urban disposable income (lagged one period). Pooled Provincial data are used, with fixed and time effects.

Table 2. Rural Households: Saving and Government Spending

\begin{tabular}{|c|c|c|c|c|c|c|c|c|}
\hline & \multicolumn{4}{|c|}{ Sample: 1996-2007 } & \multicolumn{4}{|c|}{ Sample: 2003-07 } \\
\hline & (1) & (2) & (3) & (4) & (5) & (6) & (7) & (8) \\
\hline \multicolumn{9}{|l|}{ Health } \\
\hline Estimate & 0.51 & $\ldots$ & 0.22 & $\ldots$ & 0.37 & $\ldots$ & 0.06 & $\ldots$ \\
\hline (Standard error) & $(0.59)$ & $\ldots$ & $(0.58)$ & $\ldots$ & $(0.67)$ & $\ldots$ & $(0.64)$ & $\ldots$ \\
\hline$[\mathrm{P}-\mathrm{val}]$ & {$[0.39]$} & $\cdots$ & {$[0.70]$} & $\ldots$ & {$[0.58]$} & $\ldots$ & {$[0.93]$} & $\ldots$ \\
\hline \multicolumn{9}{|l|}{ Education } \\
\hline Estimate & $\ldots$ & 0.45 & 0.49 & $\ldots$ & $\ldots$ & 0.91 & 0.90 & $\ldots$ \\
\hline (Standard error) & $\ldots$ & $(0.36)$ & $(0.38)$ & $\ldots$ & $\ldots$ & $(0.61)$ & $(0.54)$ & $\ldots$ \\
\hline [P-val] & $\ldots$ & {$[0.22]$} & {$[0.20]$} & $\ldots$ & $\ldots$ & {$[0.14]$} & {$[0.10]$} & $\ldots$ \\
\hline \multicolumn{9}{|l|}{ Health \& education } \\
\hline Estimate & $\ldots$ & $\ldots$ & $\ldots$ & 0.39 & $\ldots$ & $\ldots$ & $\ldots$ & 0.53 \\
\hline (Standard error) & $\ldots$ & $\ldots$ & $\ldots$ & $(0.29)$ & $\ldots$ & $\ldots$ & $\ldots$ & $(0.47)$ \\
\hline [P-val] & $\ldots$ & $\ldots$ & $\ldots$ & {$[0.18]$} & $\ldots$ & $\ldots$ & $\ldots$ & {$[0.27]$} \\
\hline R-squared & 0.36 & 0.37 & 0.36 & 0.36 & 0.31 & 0.32 & 0.32 & 0.32 \\
\hline \# Obs. & 285 & 304 & 285 & 285 & 150 & 150 & 150 & 150 \\
\hline
\end{tabular}

Sources: CEIC; and staff estimates.

Note: All variables are in first differences. The dependent variable is the saving rate, and government spending variables are per capita spending expressed as a share of per capita urban disposable income (lagged one period). Pooled Provincial data are used, with fixed and time effects. 


\section{REFERENCES}

Aziz, Jahangir, and Li Cui, 2007, "Explaining China's Low Consumption: The Neglected Role of Household Income,” IMF Working Paper 07/181 (Washington: International Monetary Fund).

Blanchard, Olivier, and Francesco Giavazzi, 2005, "Rebalancing Growth in China: A ThreeHanded Approach," MIT Department of Economics Working Paper No. 05-32 (Cambridge: Massachusetts Institute of Technology).

Chamon, Marcos, and Eswar Prasad, 2008 "Why are Saving Rates of Urban Households in China Rising?” IMF Working Paper 08/145 (Washington: International Monetary Fund).

International Monetary Fund, "China's Difficult Rebalancing Act," IMF Survey Online, September 12, 2007. Available via Internet:

http://www.imf.org/external/pubs/ft/survey/so/2007/CAR0912A.htm

Wangstaff, Adam, Magnus Lindelow, Shiyong Wang, and Shuo Zhang, "Reforming China's Rural Health System,” July 2009 (Washington, DC: The World Bank). 